\title{
Murilo Mendes, colecionador ${ }^{1}$ \\ Maria de Lourdes Eleutério
}

\author{
Souvenir objet que rappelle un fait. \\ Objet donné par une personne pour qu'on se souvienne d'elle \\ Les souterrains des souvenirs (des châteaux forts) allaient s'ouvrir au au loin \\ Dans la campagne \\ Jean Arp
}

Os versos apostos em epígrafe, Souvenir Mendés, feitos para homenagear Murilo Mendes, expressam a intensa manifestação de trocas de atenção e reconhecimento que estão na base das relações de amizade entre artistas. Através de suas produções: verso, prosa, pintura, desenho, partitura, escultura, gravura, os amigos-artistas constróem convivências e inspiram obras, muitas vezes oferecidas como testemunho do apreço mútuo. Tais presentes estão na origem de muitas coleções, nas quais o presenteado se descobre colecionador, devido ao círculo de amizades derivadas do próprio fazer artístico. Podemos estabelecer associações que delineiam a sociabilidade, tanto da afetividade quanto do percurso do trabalho, daqueles que possuem um acervo feito de lembranças, no qual os objetos constituem um verdadeiro mapeamento de reciprocidade de afetos e interesses.

Os colecionadores que não pertencem ao círculo dos produtores de arte norteiam suas escolhas por critérios mais objetivos, tais como: um determinado tema ou período, um artista específico, séries de um certo pressuposto estético, enfim, reunindo objetos de uma mesma natureza e que façam sentido entre si. Os colecionadores-artistas são singulares, fazem um tipo diferenciado de colecio-

(1) Os quadros reproduzidos no interior do artigo estão indicados por asterisco. (Nota Edit.) 
nismo, pois seus acervos se constituem sob uma trama de influências das quais afloram processos criativos. A atividade de colecionar é mais comum entre eles do que percebemos habitualmente, e se ela nos revela sempre quem a amealhou, no caso desses homens e mulheres que dedicam a sua vida ao processo criativo em artes, tal atividade nos possibilita entender os projetos estéticos de uma época.

Entre os brasileiros, podemos citar, por exemplo, Oswald de Andrade, em cujo acervo muitas das obras foram presentes de amigos pintores ou mesmo da esposa pintora, Tarsila do Amaral. Sem contar as telas que o homem do Pau Brasil adquiriu, como por exemplo Ceia de John Graz, pela qual pagou com um terreno no qual o pintor suiço fez construir a casa em que fixou residência no Brasil. ${ }^{1} \mathrm{O}$ pai da Antropofagia, já no fim da vida, em suas memórias, define a grande importância das peças de sua coleção afirmando:

Fito nas paredes do living espaçoso as minhas altivas bandeiras. São os quadros, as obras-primas da pintura moderna de que em breve vou me desfazer. São os estandartes levados na guerra que foi a minha vida. Um grande Chirico (...) É um dos quadros que criaram em Paris o Surrealismo (...) a obra-prima de Tarsila, O sono. Duas jóias de Cícero Dias, (...) um guache de Picasso em azul e negro. São as minhas bandeiras que contam que nunca abdiquei na luta feroz de meus dias. ${ }^{2}$

Notemos que o Chirico aqui referido é uma das telas mais importantes do artista e da modernidade, uma das únicas a reunir todos os símbolos presentes na desconcertante produção da primeira fase do pintor, aquela considerada verdadeiramente inventiva. Ao mencionar que em breve se desfaria do acervo, Oswald mostra uma realidade muito comum ao meio artístico. Em dificuldades, os artistas vendem seu patrimônio, às vezes por preços irri- 
sórios, para colecionadores ou instituições de arte. Assim, objetos, não raro com dedicatórias, testemunhos singulares de histórias de amizade e homenagem, ganham preços determinados pela crise financeira pela qual passa seu proprietário.

Muito do que se encontra nos museus brasileiros foram doações ou vendas originadas de tais coleções. Parte substancial desses acervos devemos aos modernistas. Além de Oswald, lembremos por exemplo de Tarsila do Amaral e da mecenas D. Olívia Guedes Penteado, que ao retornarem ao Brasil, vindos da Europa nos anos 20, traziam os primeiros impactos da renovação em curso nas artes visuais. Nos anos 50, em dificuldades, Tarsila vende a marchands estrangeiros a sua coleção que foi revendida nos EUA e Europa. A pintora foi proprietária, apenas a título de exemplo, da famosa tela Torre Eiffel, de Delaunay. Desta vez, foi Tarsila quem comprou uma casa com tal venda. ${ }^{3}$

Já a coleção de Guilherme de Almeida teve melhor sorte, não se dispersando. Encontra-se ainda hoje na própria morada do poeta, preservada nas mesmas condições deixadas desde seu falecimento. Na residência do autor de Soror Dolorosa vemos, além de cerca da 150 obras de artes visuais, a maioria assinada pelos modernistas: Anita Malfatti, Lasar Segall, Di Cavalcanti, (os três fizeram retratos de Guilherme de Almeida), Victor Brecheret, Tarsila do Amaral, Antonio Gomide, Paim Vieira, entre outros, a biblioteca, o mobiliário e uma infinidade de objetos, especialmente referentes à Revolução Constitucionalista de 32 e à Comemoração do IV centenário de São Paulo. Tal acervo compunha o ambiente no qual viveu o escritor, e em grande parte é constituído de lembranças de amigos. ${ }^{4}$

Não se pode deixar de mencionar o rico patrimônio que constitui o Museu Lasar Segall, embora a preponderância dos objetos nele reunidos seja de produção do próprio artista e não de uma coleção feita a partir de obras oferecidas a ele. Reunir obras de arte 
moderna, especialmente européia, num primeiro momento, era uma preocupação para os modernistas, visando à formação de um gosto não acadêmico entre nós.

Mário de Andrade, como sabemos, recolheu sistematicamente muitas séries de objetos, comprando-os em grande parte. Mas sua coleção revela também o itinerário das amizades que constituiu ao longo da vida através dos presentes recebidos.

É esta a essência da coleção do poeta mineiro Murilo Mendes. Há diferenças substanciais entre a coleção de Mário e de Murilo. No acervo do primeiro, em artes plásticas, predominam artistas brasileiros, além da preocupação com cultura popular e a etnografia brasileiras. Já o autor de $A$ idade do serrote reuniu, de modo mais acentuado, obras que indicam suas amizades mais próximas ou artistas que apontam para sua longa estada na Europa, conferindo maior contemporaneidade à sua coleção.

Entretanto, há muitas semelhanças entre estes dois modernistas. Ambos fizeram crítica de artes plásticas e, amantes extremados da música, escreveram sobre ela. Tanto um quanto outro tiveram convivência profícua com outros nomes da intelectualidade brasileira e internacional. Suas coleções nos mostram a preocupação que tinham na constituição do que nos legaram, para além de suas próprias obras, como nos lembra a pesquisadora Maria Cecília França Lourenço, ao dizer:

Mendes, Segall e Mário eram conscientes de sua importância na história e organizaram, com ajuda ou sós, suas marcas pelo Mundo ${ }^{5}$

Os três se dedicaram à organização de seus acervos, e estes se concretizaram em ricos centros de pesquisa. Acrescente-se então, às semelhanças já apontadas, esta que nos permite indagar sobre a importância para a sociedade — da época e atual — da reunião de bens culturais amealhados por esses e outros artistas e inte- 
lectuais. Temos hoje, nas instituições às quais pertencem tais materiais, fonte permanente de encontro e descoberta desses escritores e do contexto em que criaram suas obras.

Pensemos ainda que se o ato de colecionar é o ato de eleger, é também querer ser reconhecido pelo fato de reunir objetos únicos. É ainda o de constituir um retrato de si mesmo através do legado que foi coletado. Ao analisar as séries, a relação entre os objetos colhidos, ampliamos os saberes que podemos obter sobre as trajetórias pessoais e de sua época. Assim é que as amizades que buscam nas artes suas afinidades eletivas, trocam não só influências intelectuais mas objetos como forma de admiração. Murilo Mendes reuniu um expressivo conjunto de quadros, gravuras, desenhos, livros raros, ilustrados por artistas importantes, como o demonstram as dedicatórias que delineiam o percurso das amizades que cultivou.

Para observarmos essas amizades enquanto pressuposto para a articulação das influências recebidas e das coleções formadas, tomamos a definição que Davi Arrigucci Jr. elaborou para a amizade entre Murilo Mendes e Ismael Nery, qual seja, a da

\footnotetext{
amizade como um sentimento capaz de ampliar as zonas de experiência e do saber, de incentivar o sonho e a imaginação e, ao mesmo tempo, de animar o desejo de realização pelo trabalho construtivo comum. ${ }^{6}$
}

A produção de Murilo Mendes e a coleção muriliana estão no centro da interlocução com os amigos. Destaquemos os mais conhecidos encontros que fomentaram "experiências e saberes." Primeiro, o pintor-poeta Ismael Nery. Com a morte prematura deste, estreita-se a amizade com o também pintor-poeta Jorge de Lima, o profícuo encontro transformado em amizade duradoura com 
o casal Vieira da Silva-Szenes, e ainda, os laços estabelecidos com o pintor Alberto Magnelli.

O livro Recordações de Ismael Nery, reunião dos artigos publicados por Murilo sobre o antigo, é o registro cabal do estímulo recíproco de uma amizade que durou 13 anos. Podemos apreciar em tais "recordações", o profundo traço muriliano compondo o complexo perfil do amigo de múltiplas habilidades. Mas o comovente memorial do poeta é fundamentalmente um itinerário de seu aprendizado estético, no qual vislumbramos, página a página, as repercussões que o encontro projetou em sua vida e sua obra.

Murilo exalta o companheiro de trabalho da Diretoria do Patrimônio Nacional e de caminhadas diárias:

\begin{abstract}
Que experiência incomparável para um jovem poeta vindo pouco antes da pequena cidade natal: o contato direto com um artista fervendo de idéias, um homem que apesar da sua juventude se revelaria logo um mestre de vida, um filósofo original, um comentador das formas, um vasto espírito em que as antinomias se fundiam! Passear pela cidade com Ismael Nery era de fato um prazer dos deuses.
\end{abstract}

Reafirmando os ensinamentos nos passeios vespertinos.

\footnotetext{
Ele me ensinou a ver (...). Nesses passeios comecei a descobrir as relações de afinidade entre o mundo físico e o moral, a interpretação e fusão das formas, as diferenças entre forma e fôrma, estudo de interesse inesgotável. ${ }^{7}$
}

Os diálogos com o amigo eram tão importantes que Murilo tentava registrá-los: "Eu ia a sua casa quase todas as noites e, ao voltar, muitas vezes abria o caderno para resumir a conversa... Tributários diretos dessas conversas são seus livros Poemas e $O$ Visionário, nos diz o poeta. 
A retribuição e o agradecimento para tanta influência confessa veio, como vimos, através dos candentes artigos enfeixados em volume sob o título de Recordações de Ismael Nery, bem como pela divulgação do trabalho do amigo, quando em 1935 Murilo organizou uma exposição do artista, então completamente esquecido, e também ao publicar seus versos em revistas.

O poeta mineiro fez paciente recolha dos desenhos que Ismael Nery jogava fora. Foi ele ainda, segundo Emmanuel, o filho de Nery, o responsável pela preservação dos trabalhos deixados por seu pai. Em suas memórias Emmanuel afirma: Murilo salvou a maioria das obras escritas e pintadas por meu pai (é) o único responsável pela preservação do acervo." 18 Lembremos que antes de morrer Nery rogava insistentemente que o amigo destruísse seus quadros e desenhos. A falta de coragem de Murilo resultou no enriquecimento de nosso patrimônio artístico. Colecionador, ele reuniu e preservou a produção do amigo e se desfez dela, em gesto magnânimo, ao devolvê-la à família. E como não poderia deixar de ser, Murilo fez poemas para Ismael nos quais sintetiza toda a grandeza que vê no amigo, ${ }^{9} \mathrm{e}$ Ismael, por sua vez, pintou e desenhou Murilo, além de criar a tela Composição surrealista, de 1928, em sua homenagem.

Após a morte de Ismael Nery, o espírito inquieto do autor de Mundo Enigma encontrou ressonância em outro amigo que trazia certa semelhança com Nery no que concerne aos múltiplos interesses. Afinal, Jorge de Lima era poeta, pintor e escultor, compunha versos impregnados pela mística e pela religião, e ainda, pela forte influência surrealista. Acrescente-se ser ele um profundo conhecedor de música erudita, e, como Mendes, fez migrar para a produção poética o conhecimento musical que possuía. Além disso, Jorge também fez crítica de arte, era médico e político. ${ }^{10}$ Tantos interesses e atividades foram sintetizados em versos nos quais Murilo alude aos "tempos multiplicados" de Jorge. ${ }^{11} \mathrm{O}$ exercício do olhar e o aprendizado estético de Murilo Mendes ganham novas perspectivas 
vindas do encontro com Jorge de Lima, quando este alagoano chega de sua terra para instalar-se no Rio de Janeiro em 1931. A partir de então, interessando-se cada vez mais por arte, liga-se ao poeta mineiro.

É certo que Max Ernst era referência para Murilo desde que Nery trouxera o livro de fotomontagens La femme 100 têtes de uma de suas viagens à Europa nos anos 20. O interesse permanece e junto a Jorge de Lima, igualmente impregnado pela obra do pintor alemão, Murilo desenvolve trabalhos com grande proximidade, como podemos observar através da produção realizada nos anos 30 e 40. A obra A pintura em pânico (1943) de Jorge de Lima, cujo título é referência à Poesia em Pânico (1937) de Murilo, traz o prefácio deste e é composta de fotomontagens para as quais o próprio Murilo colaborara. No texto, Murilo Mendes indica a grande importância que teve para si e para Jorge,

La femme 100 têtes: "O livro de Max Ernst inspirava-me. Faltavamme, porém, a paciência, a perseverança. Jorge de Lima tem tudo isto, e mais ainda. Começamos juntos o trabalho. Mas dentro em breve ele ficava sozinho. ${ }^{12}$

A estudiosa da obra de Jorge de Lima, Ana Maria Paulino, enfatiza a importância da colagem, que devemos entender aqui como fotomontagem, para Lima:

a percepção do poeta se dá como numa tela. Ou uma colagem, onde as formas vão se superpondo umas às outras, à maneira dos sonhos. ${ }^{13}$

A assertiva aplica-se a Murilo Mendes, que mesmo não tendo ido avante na realização das fotomontagens, usou o processo como referencial poético. A colaboração intensa e profícua entre o poeta mineiro e o alagoano teve também nos poemas de Tempo e Eternida- 
de, segundo Alexandre Eulalio, uma experiência criadora considerável. ${ }^{14}$

Deve-se creditar parcialmente a Jorge de Lima o entusiasmo muriliano por Ernst. Assim como Murilo passeava todas as tardes com Ismael Nery e freqüentava quase que diariamente sua residência, o convívio com Jorge de Lima se deu em inúmeras ocasiões no consultório médico deste último, misto de espaço profissional e local de reuniões, além de atelier de pintura e ambiente que se assemelhava a uma loja de antigüidades, onde o assunto era necessariamente arte. ${ }^{15} \mathrm{Em}$ tais reuniões um dos temas caros deve ter sido seguramente Max Ernst.

Ernst, um dos fundadores do grupo dadaísta de Colônia, é um dos criadores da técnica de colagem. Na verdade, a colagem ernstiana é uma fotomontagem com ilustrações recortadas de enciclopédias e revistas, e recompostas com traços marcados a crayon para imprimir contrastes acentuados. A coleção Murilo Mendes possui do artista a colagem Deshabillés* de 1920 e a litografia Danse, sem data. $O$ pintor alemão, aliás, tinha uma personalidade bem ao gosto muriliano. Experimentador infatigável de vasta cultura, conhecedor de arte, filosofia, ocultismo e psiquiatria, compunha o perfil multifacetado dos artistas admirados por Murilo que nos conta, em um poema da série retratos-relâmpago, o encontro que teve com Ernst, ocasião em que lhe disse como uma de suas obras, consideradas das mais perturbadoras do surrealismo, o impressionara:

Confesso-lhe o quanto lhe devo, o coup de foudre que foi para o desenvolvimento da minha poesia a descoberta do seu prodigioso livro de fotomontagens La femme 100 têtes. $^{16}$

Outra influência, tanto para Murilo quanto para Jorge de Lima, é Giorgio De Chirico. Para o primeiro, De Chirico é funda- 
mental como podemos observar no retrato-relâmpago dedicado a ele:

Alguns poemas de minha fase inicial descendem — direta ou colateralmente - do primeiro De Chirico, aquele dos manequins, dos interiores "metafísicos", do deserto melancólico das praças, italianas ou não, transpostas a uma situação particular de sonho, o poeta da Grécia heterogênea, metal e plástica.

Os versos murilianos sintetizam a vida se transfigurando em obra do pintor grego-italiano que integra à primeira fase de sua pintura, a vivência em sua terra natal onde passou sua primeira infância desenhando ruínas gregas e introjetando mitos. Acrescentese às ressonâncias da vivência na produção pictórica de De Chirico, a posterior experiência na Itália, afinal suas raízes estavam lá, e o período passado na Alemanha, onde cursou Filosofia e, apreciador de Nietzsche, colocou em sua pintura o que chamou de "vontade de potência criadora". Todo esse itinerário influi consideravelmente em sua obra até 1920, sobretudo, nutrem sua metafísica. Entre os surrealistas o pintor é referência obrigatória com sua obras enigmáticas e Murilo nos lembra disto, ao mencionar também, no mesmo texto, o seu interesse por esta estética:

Desde a primeira época da formação do surrealismo informei-me avidamente sobre essa técnica de vanguarda.

Em seguida, o poeta, assim como fizera no retrato dedicado a Ernst, nos relata as impressões de seu encontro com De Chirico.

Instalando-me em Roma, logo contactei escritores e artistas. Fui visitar De Chirico (...) Claro que estava informado sobre sua involução, (...) apesar disto, julguei que seu ambiente conservasse vestígios dos 


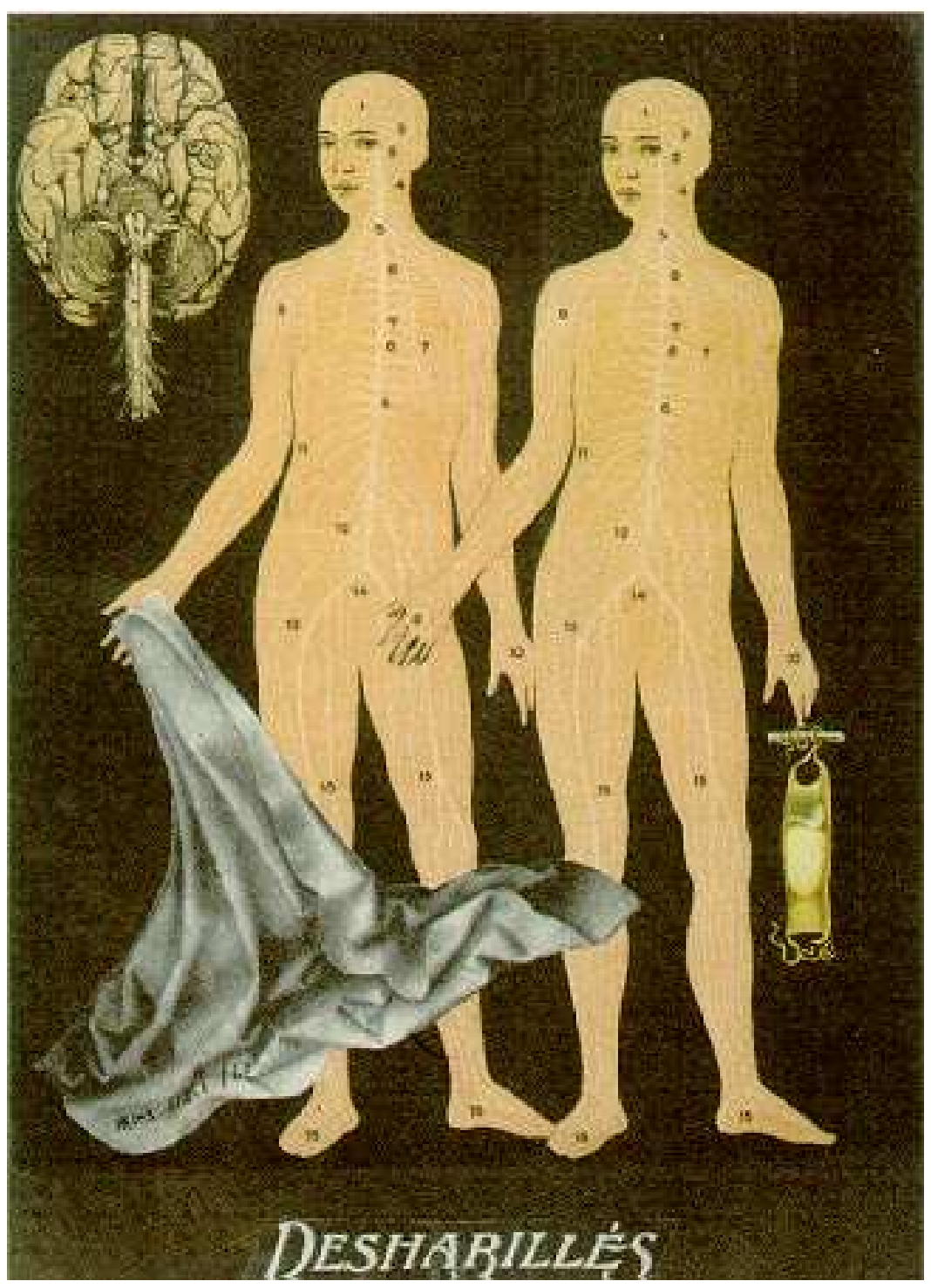


tempos do primeiro Chirico. Enganei-me: os móveis, a decoração, os quadros do próprio pintor (nus medíocres, auto-retratos com chapéus emplumados), aproximavam-se do gosto burguês.

A coleção Murilo Mendes tem apenas a litogravura Manequins* do artista cuja presença é tão marcante para o poeta. Talvez, a razão disso esteja no parcial insucesso da visita. Primeiro porque o Chirico encontrado, através da descrição em tom de julgamento do ambiente doméstico do pintor, não era aquele que tanto interessara Murilo nos anos 20 e 30, e segundo porque o "orgulho e excessivo nascisismo"17 de De Chirico inviabilizaram o projeto de iniciar uma amizade e, decorrência disso, de enriquecer a coleção com os presentes que provavelmente viriam da relação de amizade.

O que é muito interessante nos retratos-relâmpago é que neles lemos confluências, isto é, ao mesmo tempo em que lemos sobre o objeto da apreciação, sabemos o percurso no qual Murilo se alimentou para conhecer e fazer julgamento estético como o ocorrido no retrato de De Chirico. A homenagem é assim, também um juízo crítico, além disso, vistos em seu conjunto, os retratosrelâmpago possibilitam uma apreciação concisa de toda a história da arte.

Ao sintetizar as influências pictóricas que o impregnam, particularmente Chirico e Ernst, Murilo acrescenta Tarsila do Amaral e Cícero Dias, como referências nacionais a iniciarem a interação inspiradora entre pintura e poesia. (Lembremos a similitude com as considerações de Oswald colocadas acima).

Partindo de Tarsila a pintura começa a influir na poesia brasileira. $\mathrm{O}$ quadro Abapuru decide a vocação de Raul Bopp. Acha-se nas origens de Cobra Norato, outros do mesmo ciclo suscitarão textos de Mário de Andrade (...) Telas como Distância, A cuca, O sono, A negra, viajarão clandestinamente ao longo dos meus Poemas. Alternando com 
outras de Max Ernst, do primeiro Cícero Dias e do primeiro De Chirico. $^{18}$

Em Poemas, seu livro de estréia em 1930, já se delineia o processo dialógico entre literatura e artes plásticas, que Murilo empreenderia, como podemos aferir nos versos para Cícero Dias, por exemplo. ${ }^{19}$ Aliás, procedimento caro desde há muito aos escritores e pintores, como é possível observar no elucidativo artigo de Alexandre Eulalio sobre o tema do olhar impregnado de imagens que transbordam para a escritura ficcional. Eulalio nos apresenta um "caso-tipo", isto é, uma análise paralela da obra O último baile da monarquia do pintor Aurélio Figueiredo (também ficcionista e poeta), e seu suposto "modelo operativo", o capítulo da obra Esaú e Jacó, de Machado de Assis, que trata do referido baile, para demonstrar as reciprocidades inspiradoras que se estabelecem. Entre muitos outros exemplos de leitura intertextual indicados no ensaio, encontram-se o pontilhismo de viés italianizante produzido por Elyseu Visconti, que estaria na raiz do texto Casos e Impressões de Adelino de Magalhães, ou a poesia de B. Lopes repercutindo Facchinetti ou mesmo Castagneto. ${ }^{20}$

A coleção de Murilo foi acrescida de várias lembranças advindas da amizade com o casal Vieira da Silva-Szenes, registradas em telas nas quais retratou-se Murilo e também sua esposa Maria da Saudade, e ainda em vários desenhos que denotam a informalidade e camaradagem da convivência entre os casais, como por exemplo os poucos e precisos traços desenhados por Szenes e que configuram Murilo com a mão direita segurando o rosto e que o próprio poeta intitulou "Murilo Mendes ouvindo música".* Obras que se gostam de ver não pelo apuro estético mas pela lembrança que evocam, e que simultaneamente proporcionam o desenvolvimento do olhar crítico sobre artes visuais e propiciam a criação poética. 


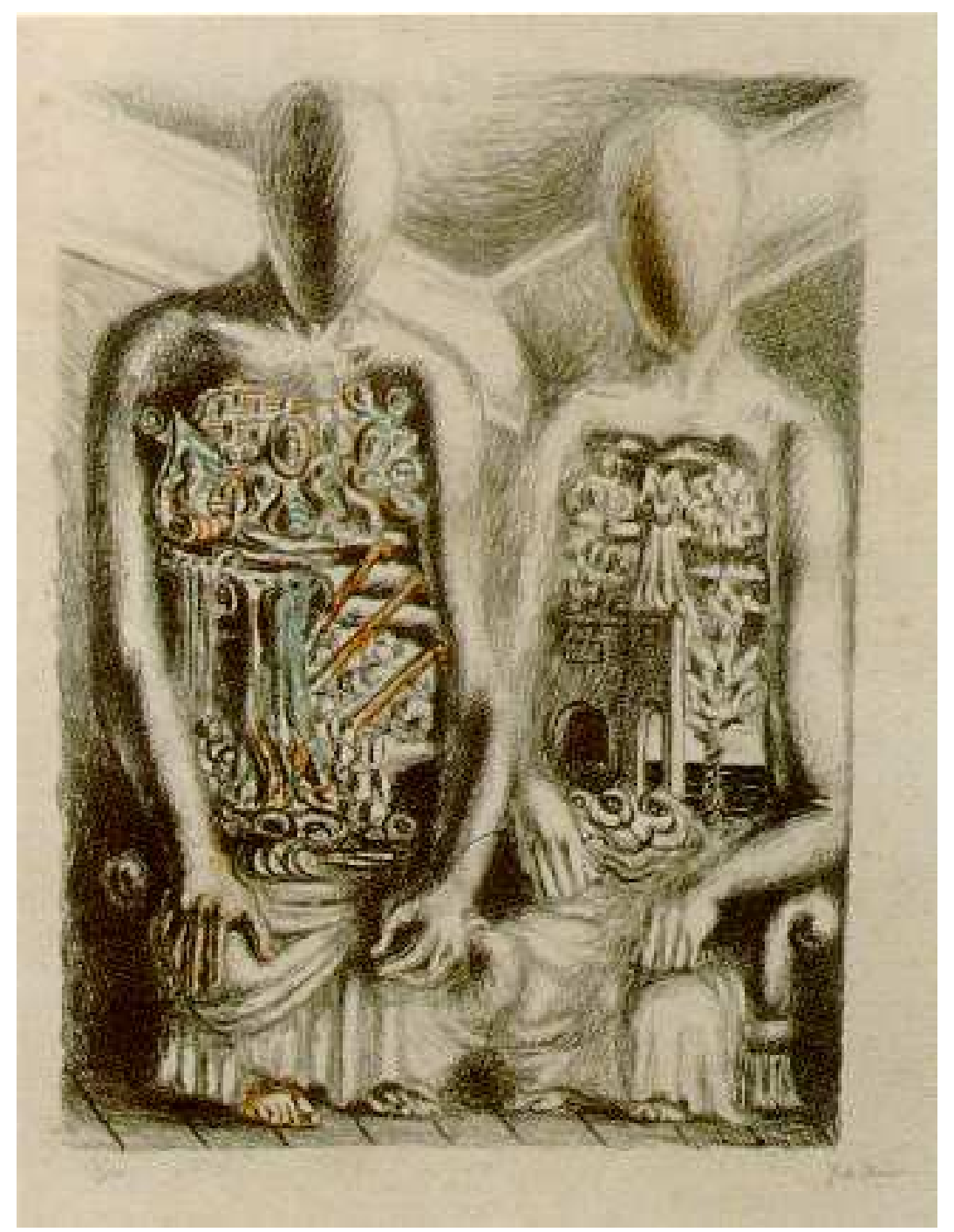




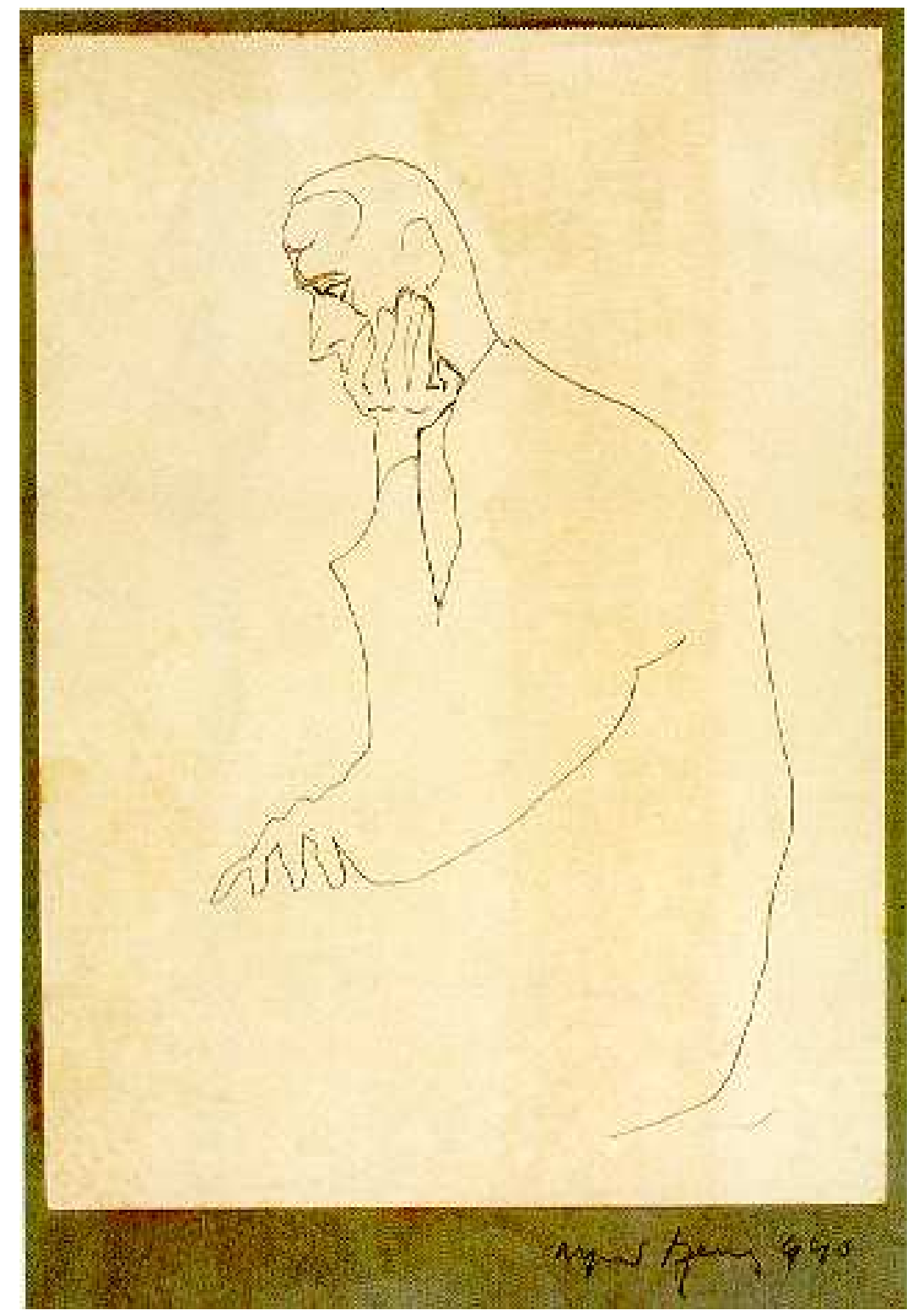


Maria Helena Vieira da Silva, considerada a maior pintora portuguesa desde século, aluna de Léger, e seu marido, o judeu húngaro Arpad Szenes, chegaram ao Brasil em 1940 fugindo da guerra, depois de Portugal não ter dado asilo a Szenes. Viveram aqui por sete anos desde 1940 enfrentando dificuldades pois não conseguiam vender suas telas e foram ajudados por alguns artistas, entre eles, Murilo Mendes, que levou o casal para morar na mesma pensão em que o poeta residia no Rio de Janeiro. Szenes ilustrava livros para editores brasileiros e Maria Helena fazia vasos de cerâmica para sobreviver. Murilo providenciou junto ao amigo Carlos Drummond de Andrade, então chefe de gabinete do ministro da Educação Gustavo Capanema, uma exposição dos trabalhos de Vieira da Silva para que ela ficasse conhecida, redigindo também o texto de apresentação da mostra. Mas nosso meio artístico e cultural era muito restrito para apreciar a artista. Em Paris, Szenes, aliás dos melhores representantes da Escola de Paris, conheceu a portuguesa Vieira em 1929, ambos alunos de Léger que convivem com importantes nomes do surrealismo, especialmente Max Ernst.

Depois da pensão, e até o retorno à França em 1947, Vieira Szenes moraram no morro de Santa Tereza onde se reuniam freqüentemente com um grupo de jovens artistas como Carlos Scliar, Almir Mavignier e Lygia Clark. A volta à Europa não significou o arrefecimento da amizade, até porque, tempos depois, Murilo e sua esposa seguiriam também para o Velho Continente. Depreendemos, ao observarmos a coleção muriliana, a continuidade do relacionamento através dos vários presentes enviados por ocasião de aniversários do poeta mineiro ou de sua esposa. Murilo registrava sempre as circunstâncias da oferta como podemos, por exemplo, verificar no reverso de um guache realizado por Vieira da Silva: "Para Mutilo no dia 13 de maio de 1965. MHVS Paris". O presenteado, por sua vez, impulsionado pela idéia de registro tão cara aos colecionadores, apõe em seguida: Enviado de Paris a Roma no dia do 
meu aniversário, $196521 \mathrm{E}$, naturalmente, a recíproca de ofertas se consubstanciava em versos de Murilo para o casal. ${ }^{22}$

Colecionar é também ordenar o mundo, aprofundar o conhecimento e o apuro estético. Assim sendo, analisar as peças que compõem uma coleção é atar liames que possibilitem entender o caráter das escolhas daquele que constituiu uma coleção. No caso dos colecionadores-artistas, é também perscrutar o seu processo criativo, visto que a coleção, na maioria das vezes, resulta do círculo de amigos que se compõe, e não de objetos que se escolhem. Se a função de uma obra colecionada é significar, quanto maior o significado menor é a sua utilidade prática. Todavia, os colecionadores-artistas redimensionam a condição funcional dos objetos que possuem, sob um aspecto porque o acervo é de objetos presenteados, sob outro aspecto porque estes lhes são vitais para a criatividade artística.

Habitualmente um colecionador encomenda um retrato de si mesmo para ocupar um lugar privilegiado na coleção. Mas os colecionadores-artistas têm sempre vários retratos feitos de si, já que a função do retrato nesse caso é justamente a de servir de presente. $\mathrm{Na}$ coleção Murilo Mendes vemos o poeta pintado por Guignard em 1930 e Portinari no ano seguinte. Encontramos o desenho Cabeça de Murilo Mendes de 1951 realizado por Flávio de Carvalho, além dos muitos registros feitos pelo casal Vieira-Szenes. Parece que os amigos retratistas procuram uma diversidade de faces dos retratados, como podemos inferir do conhecido comentário feito por Mário de Andrade sobre os retratos que dele fizeram, entre eles, os realizados por Segall e Portinari. Mário os confronta: o primeiro pintou-o "feio e sensual, a parte Diabo". Já Portinari teria privilegiado a "parte anjo", e segundo o escritor "o mais certo porque é o en que en gosto". Numa lista incompleta podemos lembrar que o modernista paulista foi retratado por Anita, Tarsila, Di Cavalcanti, Hugo Adami. 
A maior parcela do acervo constituído por Murilo Mendes se compõe de gravuras em litografia, serigrafia, água-forte, xilografia, técnicas mistas. Dos brasileiros gravuristas vemos Goeldi, Lívio Abramo, Atos Bulcão, Marcelo Grassmann, Portinari, que também ilustrou As metamorfoses, e Fayga Ostrower, que lembra ter dialogado com o poeta sobre dúvidas e problemas relativos a estilo e expressão. Colagens, aquarelas, guaches e óleos sobre tela completam a diversidade das técnicas.

Os artistas estrangeiros são maioria no acervo e quase todos estão representados por mais de uma obra, sendo que o casal Vieira-Szenes figura com mais de uma dezena. Há Arp, Braque, Picasso, Léger, Miró, Ensor, Rouault, além dos já citados. Um interessante núcleo de pintores e escultores italianos completa a coleção: Magnelli, Severini, Dorazio, Accardi, Perilli, Turcato, Franchina, Fontana, Capogrossi, Corpora, Biggi e Sanfilippo. A presença destes nomes denota o estreito diálogo mantido por Murilo com tais artistas quando residiu em Roma.

Nesse conjunto sobressai o pintor florentino Alberto Magnelli, que desenvolveu com o poeta mineiro, por cerca de vinte anos, a mais estreita amizade, atestada pela correspondência entre ambos, por fotografias, pelo substancial número de obras do pintor que o acervo abriga, assim como pelos vários textos dedicados a ele.

Magnelli, considerado uma dos mais importantes pintores italianos da Escola de Paris, expôs várias vezes no Brasil e é um experimentador do fazer artístico, como notara o próprio Murilo Mendes. Do figurativo à abstração, o pintor se dedicou a várias técnicas, colagem, desenho, guache, óleo sobre tela, serigrafia. A coleção do Centro de Estudos Murilo Mendes tem cerca de vinte trabalhos do artista, destacando-se entre eles uma colagem sobre papel com pauta musical, sem título, do ano de 1941. A dedicatória é "ai miei cari Mendes per il 13.5.65,"* data indicativa do aniversário 
de Murilo. Outro trabalho importante é o guache sobre papel sem título de 1933. Trata-se de uma obra que evoca a visita realizada pelo pintor italiano a Carrara. A famosa extração de mármore o impressionara bastante e marcaria sua obra a partir de então. Magnelli não mais voltaria à figuração, aprimorando-se no abstracionismo geométrico. No acervo Murilo Mendes temos exemplares de várias épocas de sua produção, estando representadas todas as décadas desde 30 até 70 . Sendo assim, lá encontramos o cerne da produção de um artista que atingiu a sua maturidade após a referida visita e na experiência vivida intensamente no período da segunda guerra, quando participou de pesquisas formais junto ao grupo de artistas formado pelo casal de artistas Jean Arp e Sophia Taeuber e Sonia Delaunay.

Um dos textos de Murilo Mendes que alimentam as trocas simbólicas, ao focalizar colagens de Magnelli, tece uma radiografia de como o artista-pesquisador opera as variadas técnicas que utiliza. O poeta como habitualmente faz em suas críticas de arte, destaca o caráter ordenador, construtivo, do processo criativo do autor que analisa:

\footnotetext{
No ato de criar, Magnelli se aplica totalmente à planificação do quadro como entidade autônoma (...) é o arquiteto vigilante de seus quadros, o coordenador dos princípios analíticos que sustentam uma estrutura compacta (...).

Reafirmando em versos a apreciação,

fiel à própria disciplina,

Domina o tempo/constrói o espaço

Com instrumentos da tradição 23
} 


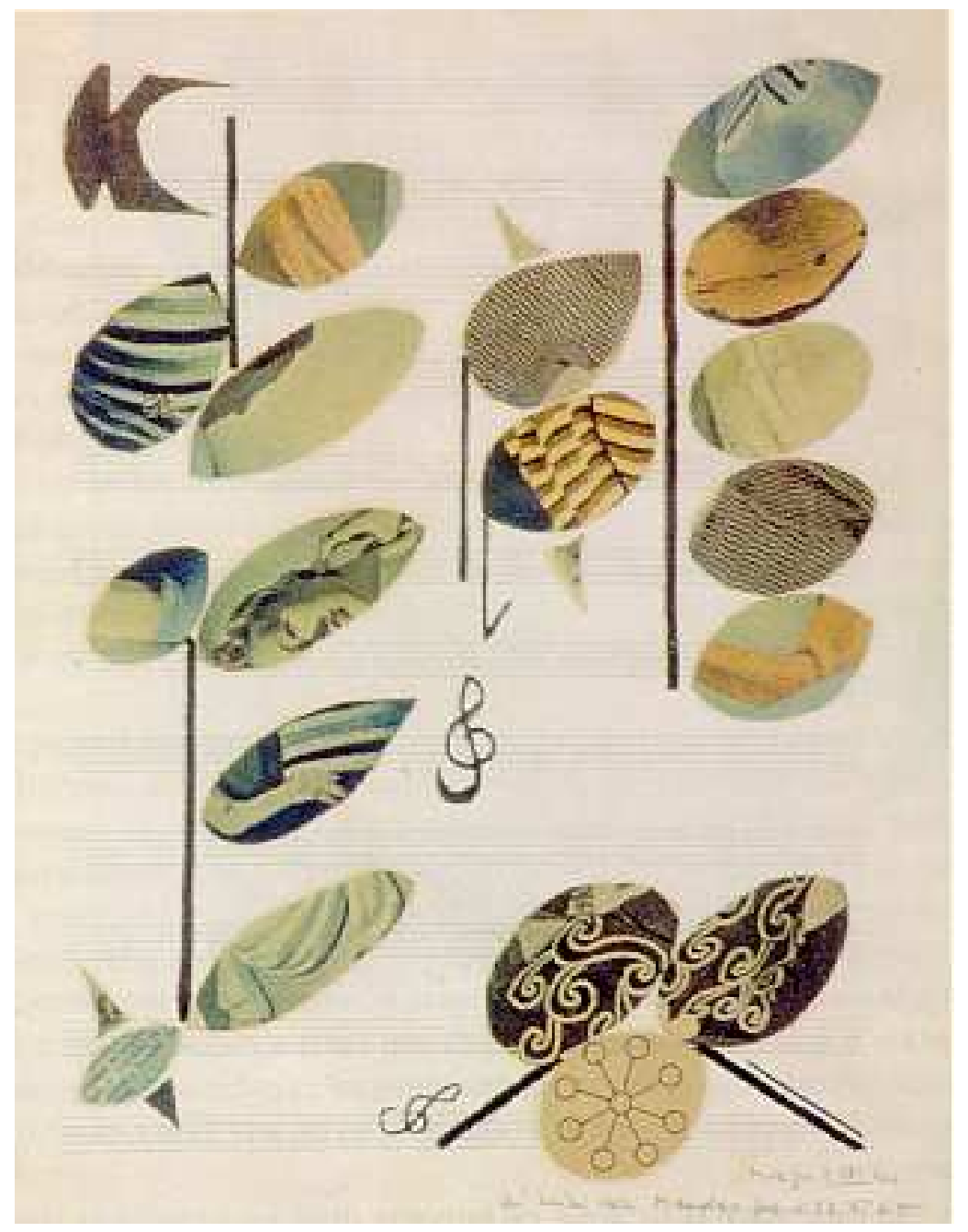


Murilo escreveria outros textos sobre o amigo; "Alberto Magnelli" em $A$ invenção do finito e "Magnelli" em Papiers, com um argumento fulcral para a definição de Magnelli: "Um homem habitado pela contínua necessidade da invenção artística."13 Podemos tomar a amizade com Magnelli, e todas as outras que esboçamos aqui, como peculiares por terem um traço em comum de extrema relevância para o poeta de Poliedro, qual seja, a do caráter de experimentação que aqueles que o cercam têm em relação a vida e à arte. $\mathrm{O}$ amálgama dessas relações é a pesquisa. Portanto, a condição de pesquisador é inerente a Magnelli, e assim entendemos o destaque dado por Murilo à coleção de arte negra que o pintor mantém em sua residência em Paris como fundamental para sua formação e criação. Uma coleção de obras de arte desempenha papel relevante na construção do olhar.

Acrescente-se, então, à idéia de pesquisa, a preocupação perene do poeta com a aprendizagem do olhar. Magnelli parece potencializar em si a "qualidade do olhar", ou seja: "o olho armado" que Murilo Mendes atribui a si mesmo. O pintor teria uma visão que

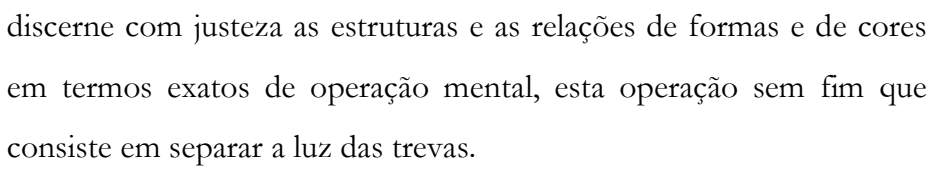

Podemos entender também a proposta de aprimoramento estético do olhar através das sucessivas visitas empreendidas pelo poeta aos pintores, como já vimos no caso de Ernst e De Chirico. Murilo visitou várias vezes Juan Miró, Jean Arp, Braque, Magritte, entre outros. Muito da obra do poeta, especialmente os retratosrelâmpago, registram as circunstâncias dos encontros e revelam a intensidade dos laços estabelecidos, e portanto da amizade concre- 
tamente visível, simultaneamente nos objetos pictóricos presenteados, e nos poemas, também feitos para presentear.

Sabemos ter sido a casa de Murilo em Roma um local de reuniões. O crítico de arte Mário Pedrosa, amigo de juventude do poeta, nos diz que a elas acorriam sobretudo artistas plásticos e acrescenta

\footnotetext{
Nenhum poeta ou literato brasileiro jamais teve a paixão da pintura como Murilo. Mário de Andrade também foi encantado por essa arte e sobre ela muito escreveu. Mas Murilo a vive, como um crítico especializado e, até mais! como um artista, um pintor. ${ }^{25}$
}

Nesse sentido, vislumbramos uma articulação intrínseca entre produção poética e experiência vivida através de amizades que se revestem de um caráter reflexivo conjugando o criar e o viver. Viver não só de diálogos sobre a produção, mas viver exercitando o olhar na produção. Referências, intencionalidade de citações mútuas, homenagens e dedicatórias tecem muitos caminhos que confluem para as paredes da casa de Murilo Mendes vestidas de quadros.

O conhecimento de história da arte certamente é de grande valia para o poeta e para o crítico Murilo. ${ }^{26}$ Seus textos estão crivados de referências de um conhecedor profundo dos procedimentos formais e do processo histórico das artes plásticas. Ao interessar-se pela abstração ele continua interessado na problemática que o ocupa desde sempre, qual seja, a elaboração técnica, isto é, como ocorre a interação cor, luz, forma, suporte, material empregado. Suas preocupações constantes contemplam ainda a questão tradição e ruptura e conseqüentemente os rumos da arte num mundo que se mercantiliza. Ele afirma 
Nenhum grande pintor moderno rompeu com a tradição plástica, an-

tes recuperou-a.

Todos esses interesses estão implícitos em sua obra e em sua coleção de arte. As paredes de sua residência romana mapeiam o surrealismo, o abstracionismo e o construtivismo pós-guerra. Se olharmos a coleção como um todo, talvez possamos dividi-la em dois grandes conjuntos, um figurativo e outro abstrato, no qual avultam os pintores italianos cujo destaque é Magnelli, como vimos. Os demais artistas italianos presentes na coleção contribuem para a reflexão muriliana sobre as pesquisas formais, e assim cada um tem uma função a desempenhar nessa síntese de história da arte contemporânea. Observemos por exemplo Fontana, que se ocupa das investigações sobre o espaço e a materialidade da obra. A coleção tem uma tela da série Conceito espacial: espera de 1963, ou Capogrossi que deixa a figuração para pesquisar a serialidade, como vemos no óleo sobre tela dedicado "a Murilo Mendes com ammirazione e affeto il suo Capogrossi", cujo título é Superficie 455 de 1961, enquanto que Gastone Biggi explora as possibilidades da arte cinética e suas seqüências de imagens, como atesta a obra integrante do acervo de Murilo Mendes Contínuo 78 de 1962.

Como Biggi, Dorazio e Pirilli, ambos presentes no acervo, integraram o grupo Forma Uno de 1947 dedicado à pesquisa da alteração da percepção pela cinética. Dorázio também foi um amigo próximo a Murilo, e para ele que enriquecera a coleção do poeta com uma serigrafia de 1964, este escreveu em "Dorázio e o quadro" o que poderíamos apreender como sendo para Murilo, talvez o ponto axial da questão da produção das artes plásticas naquele momento. 
Conseguirão Dorazio e mais alguns outros salvar o que parece perdido para sempre? Conseguirão despertar de novo o amor à luz? That is the question. ${ }^{27}$

Estas rápidas considerações tentam mostrar, mesmo que superficialmente, como a presença da coleção, não só para Murilo, é vital para a reflexão advinda da proximidade física com a obra de arte. Não nos esqueçamos, porém, que mesmo um colecionadorartísta, aquele que nutre seu ofício ao admirar as paredes de sua própria casa, tem atribuições, digamos comuns, a outros colecionadores: precisa ter tempo disponível, cuidado na preservação, lugar disponível e dinheiro, não sendo este último quesito tão imprescindível, graças, como vimos, às obras recebidas pelo colecionadorartista como presentes. A somatória disso é privilégio e distinção ${ }^{28}$. Uma importante função simbólica da coleção é imprimir uma aura de civilização a quem a tem, e parece que Murilo Mendes não duvida disso.

Sua coleção não se constituiu apenas de "lembranças ofertadas por amigos". O poeta, pelos apontamentos que fazia nas obras que possuía, nos mostra o quão preocupado estava com os critérios de uma catalogação, mesmo que particular. Registrava, por exemplo, as circunstâncias da procedência das mesmas. Algumas significativas compras foram realizadas por Murilo, como por exemplo, uma litografia de Picasso. No verso da peça o poeta escreveu "Achetée chez D.H. Kahnweiler. Paris. Murilo Mendes" Como sabemos, trata-se de um dos maiores marchands de arte do entre guerras, um dos primeiros a se interessar pelos modernos e cuja galeria em 1907 acolheu Picasso, Gris, Léger, Braque. Anos depois firmava contratos de exclusividade para com eles, tanto assim que os apreciadores desses artistas tinham que inevitavelmente ir a Kahnweiler para adquirir o que pretendiam. $\mathrm{O}$ marchand tornou-se então sinônimo de prestígio para quem a ele recorria. ${ }^{29}$ 
Sem a possibilidade de enriquecer sua coleção através de uma obra presenteada pelo próprio pintor, Murilo a comprou, já que, para o poeta,

Picasso é um gerador de artistas, mais poderoso que os outros (...).

Quem poderá se subtrair a sua influência?30

Infere-se então, a necessidade da complementação via aquisição, para que o acervo ganhe o sentido e a função de pensar as artes em espectro considerável, e daí Picasso não poder estar ausente.

Assim, o poeta que desde sempre deu enorme relevância ao olhar e a multiplicidade de seus interesses, enfeixados no verso " $O$ Deus, se existis, juntai minhas almas desconjuntadas" 31 , onde deixou clara a sua paradoxal personalidade que vai do católico confesso e singular ao surrealista e a tantos outros Murilos, nos legou uma outra face de si mesmo, a coleção de arte. Deslindá-la seria, segundo Baudrilhard, conhecê-lo, pois uma coleção é uma reunião de termos, "mas seu termo final é a pessoa do colecionador."32

\section{Notas}

1 In: Aracy Amaral, Artes Plásticas na Semana de 22. São Paulo: Perspectiva, $4^{a}$ ed., 1979, p. 249.

2 Oswald de Andrade, Memórias de um homem sem profissão: sob as ordens de mamãe. $3^{\mathrm{a}}$ edição do volume IX das Obras Completas, Rio de Janeiro: Civilização Brasileira, 1976. p.5.

3 Cf. Aracy Amaral, (introdução e organização) Tarsila cronista. São Paulo: Editora da Universidade de São Paulo, 2001, pp. 16,19, 26, 84.

4 No Brasil poucas são os acervos preservados, e quando o são, quase sempre não se encontram nas residências onde habitaram os escritores ou pintores. É o caso do acervo de Mário de Andrade, pertencente à Universidade de São Paulo e do acervo de Murilo Mendes, pertencente à Universidade Federal de Juiz de Fora. Segundo o Guia de 
Museus Brasileiros, os acervos reunidos e disponíveis ao público de nossos escritores são: os de Afrânio Peixoto em Lençóis o de Jorge Amado em Salvador, na Bahia; o de João Ribeiro em Laranjeiras, em Sergipe; os de Guimarães Rosa (Codisburgo); Augusto dos Anjos (Leopoldina) e Alphonsus de Guimarães (Mariana), em Minas Gerais, os de Oliveira Viana (Niterói), Rui Barbosa e Benjamim Constant na cidade do Rio de Janeiro, Rio de Janeiro. Cf. Guia dos Museus Brasileiros, USP. São Paulo: Editora da Universidade de São Paulo: Imprensa Oficial do Estado, 2000.

5 Maria Cecília França Lourenço. Museus acolhem moderno, São Paulo: Editora da Universidade de São Paulo, 1999. p. 194.

6 Davi Arrigucci Jr. "Entre amigos”, prefácio para Recordações de Ismael Nery. São Paulo: Edusp/Giordano, 1996.

7 Recordações de Ismael Nery, op. cit., respectivamente: p. 71, 28, 30, 72.

8 Emmanuel Nery, Couraça da alma, Rio de Janeiro: Editora Expressão e Cultura, 1996.

9 “Saudação a Ismael Nery” p. 115; "Ismael Nery” p. 258, In: Murilo Mendes, poesia completa e prosa, Rio de Janeiro: Nova Aguilar, 1994.

10 Cf. Ana Maria Paulino. Jorge de Lima. São Paulo: Editora da Universidade de São Paulo, (Coleção Artistas Brasileiros), 1995.

11 Murilo Mendes, “Jorge de Lima” Retratos-Relâmpago, p. 1236. Para Jorge de Lima há outros poemas: em Parábola, "Homenagem a Jorge de Lima," p. 555, em Conversa Portátil, "Jorge”, p. 1491 in: op. cit. A coleção do Centro de Estudos Murilo Mendes conta com um desenho de Jorge de Lima com dedicatória para Murilo.

12 Murilo Mendes, Nota liminar, in: A Pintura em Pânico, de Jorge de Lima. Rio de Janeiro: Tipografia Luso-Brasileira, 1943.

13 Cf. in: Ana Maria Paulino, op. cit., p. 69.

14 Alexandre Eulalio, "A obra e os andaimes, os trinta anos da morte de Jorge de Lima”, in: Escritos, Organizadores: Berta Waldman e Luiz Dantas. Campinas: Editora da Unicamp; São Paulo: Editora da Unesp, 1992, p. 477.

15 In: Ana Maria Paulino, op. cit. p. 58.

16 In: Poesia completa e prosa, op. cit. p. 1247.

17 “Giorgio De Chirico,” Retratos-Relâmpago, op. cit. p. 1270.

18 “Tarsila”, Retratos-Relâmpago, op. cit. p. 1250. 
19 Como podemos observar por exemplo em "Paisagem", "Glória de Cícero Dias", “Saudação a Ismael Nery", "Perspectiva da sala de jantar", entre outros.

20 Alexandre Eulalio, "De um capítulo do Esaú e Jacó ao painel d' o último baile”, in: Escritos, op. cit., p.367 e seguintes.

21 Outros trabalhos do casal pertencentes ao Centro de Estudos Murilo Mendes são: de Vieira da Silva com o título Romen e Julieta e a dedicatória: Rio 1941 Para a Saudade (feito com o auxilio de uma maquina de escrever. Igualmente de Vieira da Silva uma serigrafia de 1959, sem título, com os dizeres Para o Murilo. O poeta acrescenta mandado de Paris a Roma, 1959, um guache sem titulo com dedicatória em cartão que acompanha a obra: Para o aniversario. Saudade - Murilo/Murilo -Saudade. Com o abraço do Bicho, apelido da pintora, que fez também a capa de Mundo Enigma e ilustrou Janelas Verdes, de Murilo. De Szenes temos um óleo sobre tela sem título de 1948 no qual vemos sua esposa e Maria da Saudade. A tela tem a inscrição de Murilo Mendes: Maria Helena Vieira da Silva pintando Saudade.

22 Em Papiers: "Vieira da Silva" p. 1598, em As Metamorfoses: "Maria Helena Vieira da Silva" p. 351, em Mundo Enigma "Harpa-sofá”, p. 377, op.cit.

23 In: Albeto Magnelli. Collages di Magnelli. Roma: Edição II Collezionista d' Arte Contemporanea, 1970. Apud Marisa Timponi P. Rodrigues, (org.) Magnelli: mostra do acervo do Centro de Estudos Murilo Mendes. Juiz de Fora: CEMU/UFJF, 1998.

24 Respectivamente p. 1319 e 1574, op. cit.

25 Mário Pedrosa, "Murilo, poeta crítico" in: Catálo da exposição Murilo Mendes: Acervo. Juiz de Fora: Centro de Estudos Murilo Mendes, 1999, p. 37.

26 O viver na Itália já é significante, como podemos aquilatar no poema "LT a Murilo Mendes" de Alexandre Eulalio que se inicia "Os caminhos que todos/ convergem a Roma/ entre eles antigal a estradal de cinzal reall somando espaço e tempo... p. 55 in: Murilo Mendes, poesia completa e prosa, op. cit. p. 55.

27 "Dorazio e o quadro", em A invenção do finito, p. 1314, op. cit. Murilo Mendes escreve também sobre Capogrosso, Biggi e Pirelli.

28 Ver José Carlos Durant, Arte, Privilégio e Distinção, Artes Plásticas, Arquitetura e Classe

Dirigente no Brasil, São Paulo: Perspectiva/Edusp, 1989.

29 Cf. Daniel-Henry Kahnweiler in: Les marchands d'Art em France, XIX et XX siècles. Paris Éditions de la Différence, 1998. p. 132 e seguintes. 
30 Murilo Mendes. Recordações de Ismael Nery, op cit. p. 125.

31 In: “Choro do Poeta Atual”, O Visionário, op. cit. p. 207.

32 Cf. in: Jean Baudrilhard, O sistema de objetos, São Paulo: Perspectiva, 1993, p. 99. 